\title{
Platelet depletion in experimental myocardial infarction
}

\author{
S. R. Jolly, W. A. Schumacher, S. L. Kunkel, G. D. Abrams, J. Liddicoat, \\ and B. R. Lucchesi \\ Departments of Pharmacology and Pathology, The University of Michigan Medical School, \\ Ann Arbor, Michigan (U.S.A.)
}

\begin{abstract}
Summary
Accumulation of platelets in the microvasculature after acute myocardial ischemia may exacerbate tissue injury through the formation of microthrombi and by the release of vasoactive substances. To assess the role of platelets in myocardial ischemic injury and infarction, circulating platelets were reduced by $94 \pm 2 \%$ (mean \pm S.E.M.) with sheep antiserum to canine platelets. Regional myocardial ischemia was produced by occlusion of the left circumflex coronary artery (LCCA) for $90 \mathrm{~min}$ followed by reperfusion for 5 hours. Infarct size did not differ significantly between antiplatelet serum and nonimmune serum groups: $36 \pm 8 \mathrm{vs} .43 \pm 4 \%$ of the area at risk, determined by a post-mortem dual staining technique ( $p>0.05$ ). A second occlusion-reperfusion control group, sacrificed at 24 hours, did not differ from $5 \mathrm{hr}$ reperfused groups with regard to infarct size. Coronary sinus thromboxane $\mathrm{B}_{2}$ $\left(\mathrm{TXB}_{2}\right)$ concentrations were not altered significantly by platelet depletion. Histopathologic examination confirmed the presence of necrosis in the infarcted myocardium and revealed substantial leukocytic infiltration in both groups. The results suggest that circulating platelets are not required for the full expression of myocardial ischemic injury resulting from temporary coronary artery occlusion followed by reperfusion.
\end{abstract}

Key words: platelet depletion, thromboxane $\mathrm{B}_{2}$, myocardial infarct size

\section{Introduction}

There is little doubt that platelets accumulate within myocardial infarcts, as shown by experimental $(25,31)$ and autopsy (7) studies. The role of the blood platelet in the pathophysiology of developing myocardial infarcts is unclear. Platelets have been shown to form microemboli in ischemic myocardium $(25,19)$ and are known to release vasoactive substances, especially thromboxane $\mathrm{A}_{2}\left(\mathrm{TXA}_{2}\right)(13,34)$. From these actions, a negative effect of platelets on myocardial infarction might be expected. However, Wilkerson et al. (36) have shown that platelet depletion did not affect ultimate myocardial infarct size in a canine model of complete coronary artery occlusion. In experimental studies, reperfusion has been shown to produce approximately 10 -fold increase in platelet accumulation as compared to that found with permanent occlusion $(21,30)$. In the present study, the effect of antibody induced platelet depletion upon the expression of myocardial injury resulting from coronary artery occlusion/reperfusion was examined. Coronary sinus thromboxane $\mathrm{B}_{2}$ $\left(\mathrm{TXB}_{2}\right)$ concentrations also were measured as an index of the effects of platelet depletion and the subsequent development of myocardial injury due to regional $\mathrm{TXA}_{2}$ production. 


\section{Materials and methods}

\section{Occlusion-reperfusion model of myocardial infarction}

Ischemic myocardial injury was produced in dogs using techniques detailed in previous publications $(18,22)$. Male mongrel dogs $(10$ to $15 \mathrm{~kg}$ ) were anesthetized with pentobarbital sodium $(30 \mathrm{mg} / \mathrm{kg}$ intravenously), intubated, and ventilated with room air via a Harvard respirator. Catheters for drug infusion and arterial blood pressure recordings were implanted in the left jugular vein and left carotid artery respectively and were exteriorized at the back of the neck. A left thoracotomy was performed at the fifth intercostal space, the heart was suspended in a pericardial cradle, and the left circumflex coronary artera (LCCA) was isolated distal to its atrial branch and proximal to any major ventricular branches. An electromagnetic flowprobe and a micrometer-driven coronary occluder (16) were placed on the isolated segment. Coronary flow, ECG limb lead II and phasic arterial pressure were recorded continuously on a Grass Model 7 polygraph.

Dogs were randomly assigned to platelet-depleted or non-depleted (control) groups. Thirty minutes before occlusion, $4 \mathrm{ml}$ of either active antiplatelet serum or nonimmune serum was administered i.v. over a 5-minute period. Five minutes before occlusion, the occluder was adjusted to decrease the peak flow increment (reactive hyperemic response) after a 10 -second complete occlusion by more than $70 \%$ without changing resting flow. Regional myocardial ischemia then was produced by interrupting flow completely for 90 minutes. After this period of ischemia, flow was restored gradually over 30 minutes and the critical stenosis was retained for an additional 10 minutes. A supplemental dose of serum (4 ml) was given 1 hour after reperfusion.

Two control groups were employed. In one, the thoracotomy was closed and on the next day, the ECG and arterial pressure were monitored for 1 hour with the dog resting quietly in a sling. The animal was then reanesthetized, the thoracotomy incision reopened, and the heart fibrillated electrically and removed rapidly for post-mortem quantification of infarct size. Only animals which survived occlusion by at least 20 hours were included. In the other control group, and also in the platelet depleted group, animals were maintained on the respirator for 5 hours of reperfusion. The hearts were fibrillated electrically and infarct size determined. In these preparations, left ventricular end diastolic pressure and left ventricular $\mathrm{dP} / \mathrm{dt}$ were recorded continuously using a Millar micromanometer inserted through the apex of the heart.

\section{Post-mortem quantification of infarct size}

Myocardial infarct size was quantitated using a previously detailed in vitro dual perfusion technique (18). Cannulas were inserted into the LCCA immediately distal to the site of LCCA occlusion and into the aorta above the coronary ostia. The LCCA bed was perfused with $1.5 \%$ triphenyltetrazolium hydrochloride (TTC) in 20 -mM potassium phosphate buffer $\left(\mathrm{pH} 7.4,38^{\circ} \mathrm{C}\right.$ ) and the aorta perfused simultaneously in a retrograde manner with $0.5 \%$ Evans blue. Both perfusion reservoirs werc maintained at a constant pressure of $100 \mathrm{~mm} \mathrm{Hg}$ for 5 minutes. The hearts then were cut into six $1.0 \mathrm{~cm}$ thick sections, perpendicular to the apex-base axis. The area of the left ventricle at risk of infarction due to anatomical dependence on the LCCA for blood flow was identified by the lack of Evans blue stain while the regions of infarcted myocardium within the area at risk were demarcated by the lack of TTC staining.

The transverse ventricular sections were traced carefully onto clear plastic overlays and analyzed by planimetry to determine the amount of left ventricle infarcted and at risk. Data presented in the Results section have been based on such planimetric estimates. However, in several hearts from each of the three groups, infarct and risk region masses also were determined by dissection. In these instances, ventricular sections were trimmed of right ventricular, valvular, and fatty tissue. The total left ventricle, area-at-risk, and infarct were then carefully dissected and weighed. Planimetric and gravimetric determinations of percent left ventricle infarcted and percent left ventricle at risk agreed closely and could be related as follows: planimetric estimate $(\%$ total left ventricle infarcted $)=1.02 \times$ gravimetric estimate ( $\mathrm{g}$ infarct) $-1.27 ; \mathrm{r}=0.92 ; \mathrm{n}=13$.

\section{Production of platelet antiserum}

Canine-platelet-rich plasma (PRP) was separated from whole blood by centrifugation for 15 minutes at $1300 \mathrm{rpm}$. Platelets were isolated from the PRP by gel filtration chromatography using sepharose $2 \mathrm{~B}$ 
equilibrated with a calcium-free $100 \mathrm{mM}$ phosphate buffer ( $\mathrm{pH} 7.0$ ), according to a previously published procedure (27). Microscopic examination of the purified platelets revealed less than $1 \%$ contamination with other cells. Sheep were inoculated by intradermal injections of $5 \times 10^{9}$ dog platelets in incomplete Freund's adjuvant and after 25 days they were bled. The resulting sera were pooled and heatinactivated. Nonimmune serum administered to the control group was prepared by bleeding nonchallenged sheep. Circulating platelet counts were obtained from PRP prepared by collecting venous blood in $1 \mathrm{ml}$ of $3.8 \%$ sodium citrate to a total of $10 \mathrm{ml}$. This was centrifuged at $310 \times \mathrm{g}$ for 4 minutes and the platelet count per $\mathrm{ml}$ was obtained using a JT Baker MK/4Hc platelet counting system.

\section{Thromboxoane $\mathrm{B}_{2}$ assay}

A silastic cannula $15 \mathrm{~cm}$ by $2 \mathrm{~mm}$ inner diameter was inserted via the jugular vein into the coronary sinus. One milliliter of freely flowing coronary venous blood was collected drop-wise after allowing the passage of $4 \mathrm{ml}$ into a polypropylene tube containing $1 \mathrm{ml}$ of an indomethacin $(0.8 \mathrm{mg} / \mathrm{ml})$ and EDTA (5 $\mathrm{mg} / \mathrm{ml}$ ) solution at $0^{\circ} \mathrm{C}$. Samples were mixed gently and then centrifuged at $2,000 \times \mathrm{g}$ for $10 \mathrm{~min}$ at $4^{\circ} \mathrm{C}$. Plasma aliquots were stored at $-70^{\circ} \mathrm{C}$ until assay ( 1 to 2 weeks). Before $\mathrm{TXB}_{2}$ determination, samples were deproteinized with acetonitrite, adjusted to $\mathrm{pH} 3.5$ with formic acid and then extracted twice with ether. The resulting aqueous layer was washed twice with ethyl acetate, dried, and redissolved in $0.1 \%$ gel PBS for $\mathrm{TXB}_{2}$ radioimmunoassay according to Fitzpatrick et al. (9) using rabbit-derived $\mathrm{TXB}_{2}$ antibody (Upjohn). The sensitivity limit of the assay was $0.4 \mathrm{pg} / \mathrm{ml}$. The percent cross reactivities of the assay were as follows: $\mathrm{PGH}_{2}, 0.54 ; \mathrm{PGF}_{2}, 0.4 ; \mathrm{PGI}_{2}, 0.14 ; \mathrm{PGE}_{2}, 0.14 ; \mathrm{PGD}_{2}, 1.48 ; \mathrm{PGE}_{1}, 0.58$. Extraction recoveries were determined for each sample and ranged from 61 to $83 \%$.

\section{Histological examination}

A ventricular section, approximately $5 \mathrm{~mm}$ thick, was taken at the level of the posterior papillary muscle and fixed in $10 \%$ formalin. Tissue blocks were coded, paraffin embedded and cut 5 to 7 microns thick. Sections were stained with hematoxylin and eosin and examined by an observer (G.D.A.) who was unaware of the treatment code. The presence of necrosis, hemorrhage and leukocytic infiltration was examined.

\section{Statistics}

All data have been expressed as mean \pm S.E.M. Differences were considered significant when $p<$ 0.05 . Student's $t$ test was used to compare two groups. When more than two groups were being compared, one-way analysis of variance was employed followed by Duncan's Multiple Range Test. Multiple measurements within a group were compared using two-way analysis of variance.

\section{Results}

A total of 25 dogs was studied with seven, 24 hour controls; six, 5 hour controls; and eight, 5 hour platelet depletion experiments being completed successfully. Two animals, one control and one platelet depleted, were excluded because they failed to meet the criteria for entry into the study. The lack of electrocardiographic changes and epicardial cyanosis suggested that these animals did not undergo severe ischemia. The two remaining animals, one control and one platelet depleted, were excluded because they failed to survive the experimental period. Animal weight was similar in the three groups (table 1).

\section{Effects of sheep-derived antiserum on canine circulating platelet counts}

Effects of antiplatelet serum and control nonimmune serum have been examined previously in this laboratory (33). Antiplatelet serum produces greater than $90 \%$ depletion of circulating platelets for more than 24 hours without significant reduction in circulating neutrophils over an 8 hour period while control nonimmune serum is without effect on circulating platelet or leukocyte counts (33). In the present study, circulating platelet counts 
Table 1. Hemodynamic parameters and body mass in control and platelet-depleted dogs before coronary occlusion.

\begin{tabular}{|c|c|c|c|c|c|c|}
\hline Controls & n & $\begin{array}{l}\text { Body mass } \\
\mathrm{kg}\end{array}$ & $\begin{array}{l}\text { Heart rate } \\
\text { beats/min }\end{array}$ & $\begin{array}{l}\text { Mean arterial } \\
\text { pressure } \\
\mathrm{mm} \mathrm{Hg}\end{array}$ & $\begin{array}{l}\text { Heart rate } \times \\
\text { systolic } \\
\text { pressure units }\end{array}$ & $\begin{array}{l}\text { Left circum- } \\
\text { flex coronary } \\
\text { blood flow } \\
\mathrm{mL} / \mathrm{min}\end{array}$ \\
\hline $\begin{array}{l}5 \text { hours } \\
24 \text { hours }\end{array}$ & $\begin{array}{l}6 \\
7\end{array}$ & $\begin{array}{l}13.0 \pm 1.0^{*} \\
11.6 \pm 0.8\end{array}$ & $\begin{array}{l}150 \pm 13 \\
159 \pm 10\end{array}$ & $\begin{array}{l}100 \pm 7 \\
108 \pm 9\end{array}$ & $\begin{array}{l}17.0 \pm 2.5 \\
19.0 \pm 1.8\end{array}$ & $\begin{array}{l}15 \pm 1 \\
18 \pm 1\end{array}$ \\
\hline \multicolumn{7}{|c|}{ Platelet-depleted } \\
\hline
\end{tabular}

${ }^{*} \overline{\mathrm{X}} \pm$ S.E.M. is given. No significant differences were observed. $\mathrm{P}>0.05$ by one-way analysis of variance followed by Duncan's Multiple Range Test.

determined on blood samples taken 30 minutes after administration of antiserum, were reduced from $245 \pm 36 \times 10^{3}$ to $11 \pm 3 \times 10^{3}$ platelets $/ \mathrm{mm}^{3}$ PRP, a $94 \pm 2 \%$ ( $\overline{\mathrm{x}} \pm$ S.E.M.) depletion. Nonimmune serum did not alter platelet counts.

\section{PLATELET DEPLETION AND HEMODYNAMICS}

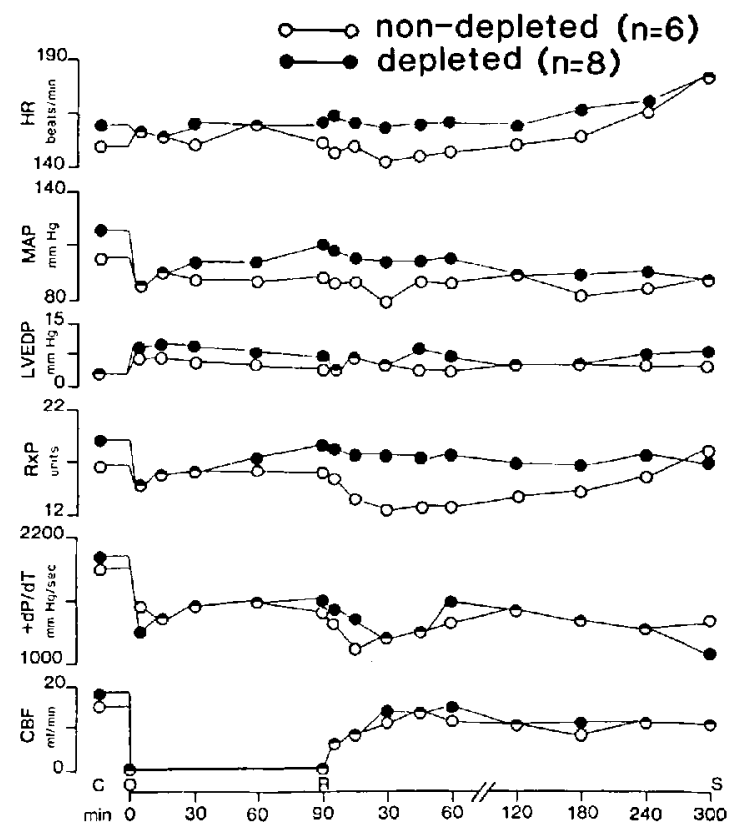

Fig. 1. Hemodynamic parameters: heart rate (HR), mean arterial pressure (MAP), left ventricular end diastolic pressure (LVEDP), heart rate $\times$ systolic arterial pressure $(R \times R)$, peak positive left ventricular $\mathrm{dP} / \mathrm{dt}(+\mathrm{dP} / \mathrm{dt})$ and left circumflex coronary blood flow $(\mathrm{CBF})$ are shown for the nonimmune serum and platelet depleted groups during the experimental period. Each point represents the mean value at that time. 


\section{Hemodynamic parameters}

Control hemodynamic parameters did not differ between nonimmune serum and plateletdepleted groups (table 1). In some animals, the injection of sheep serum, especially antiplatelet serum, produced a transient hypotension which had recovered before control measurements were made. Effects of left circumflex coronary artery occlusion and reperfusion upon hemodynamic parameters for the 5 hour reperfused groups are shown in figure 1 . Similar responses to coronary artery occlusion were observed with no significant difference detected between the groups. In the first 5 minutes of occlusion, mean arterial pressure and peak positive left ventricular $\mathrm{dP} / \mathrm{dt}$ fell while left ventricular end diastolic pressure rose. The gradual return of left circumflex coronary blood flow upon reperfusion, and the absence of a reactive hyperemia, were possible with careful control of the micrometer-driven occluder. Ventricular ectopy was observed in all animals in the first 20 minutes of occlusion and after 30 minutes of reperfusion.

\section{Myocardial infarct size}

Measurements of the percent of left ventricle anatomically dependent on the occluded left circumflex coronary artery and of myocardial infarct size are shown in figure 2 for nonimmune serum and platelet antiserum groups. There was no difference in the amount of myocardium at risk between the three groups. Myocardial infarct, determined by the dual staining technique with TTC, was $43 \pm 4$ and $42 \pm 3$ percent of the area-at-risk in nonimmune serum groups reperfused for 5 hours and 24 hours, respectively. The platelet-depleted group developed myocardial infarcts of $36 \pm 8$ percent. This small reduction, approximately $15 \%$, was not statistically significant. In light of recent criticisms of the TTC technique, as used in a 6 hour complete occlusion protocol (8), it is important that 5 hour reperfused and 24 hour reperfused infarcts did not differ with regard to ultimate infarct size.

\section{EFFECT OF PLATELET DEPLETION ON INFARCT SIZE}

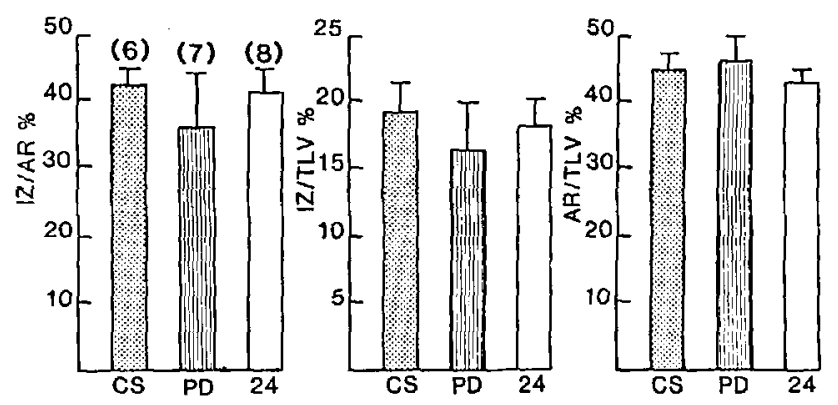

Fig. 2. Lack of effect of platelet depletion upon myocardial infarct size is shown. The three groups: nonimmune, control serum $(C S, n=6)$, platelet depletion $(P D, N=8)$ and nonimmunc control serum with 24 hour reperfusion $(24, n=7)$ are indicated by dotted, lined and open bars, respectively. The infarcted zone is normalized as a percent of the area-at-risk (IZ/AR \%, panel A) or percent of the total left ventricle (IZ/TLV\%, panel B). The amount of jeopardized myocardium is normalized as arca at risk as a percent of the total left ventricle (ARTLV\%, panel C). No significant differences were observed between the three groups. 


\section{PLATELET DEPLETION AND CORONARY SINUS TXB 2 CONCENTRATION}

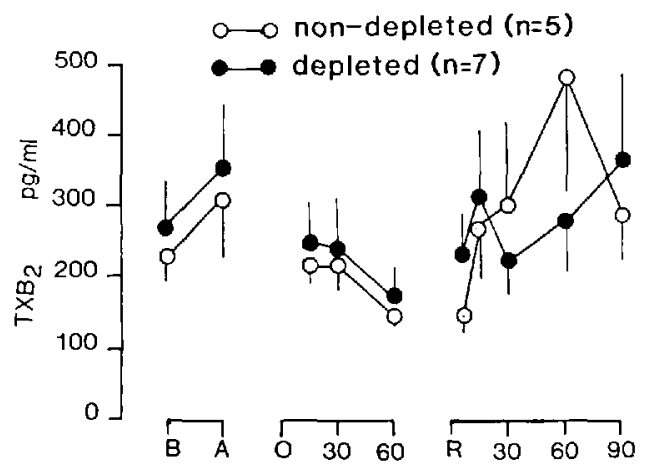

Fig. 3. Thromboxanc $\mathrm{B}_{2}$ concentrations $\left(\mathrm{TXB}_{2}, \mathrm{pg} / \mathrm{ml}\right)$ in coronary sinus blood plasma are shown for the nonimmune serum and the platelet-depleted groups. Platelet depletion did not effect coronary sinus $\mathrm{TXB}_{2}$ as judged from between group or within group comparisons. $\mathrm{TX}_{2}$ levels during left circumflex coronary artery occlusion were not different from prc-serum concentrations in either group. Both groups showed significant increases in coronary sinus $\mathrm{TXB}_{2}$ concentrations in the late reperfusion phase as compared to the plasma $\mathrm{TXB}_{2}$ concentration 60 minutes after occlusion. $\mathrm{B}=$ baseline; $\mathrm{A}=$ serum; $\mathrm{R}$ $=$ reperfusion. Time in minutes is shown on the abscissa.

\section{Thromboxane $B_{2}$ in coronary sinus plasma}

$\mathrm{TXB}_{2}$, the stable degradation product of $\mathrm{TXA}_{2}$, was examined in coronary sinus plasma samples. Before serum administration no difference in plasma $\mathrm{TXB}_{2}(\mathrm{pg} / \mathrm{ml})$ was observed between groups: platelet depletion $(270 \pm 66, n=7)$, nonimmune serum $(236 \pm 40, n=5)$. The effect of depleting circulating platelets by $94 \%$ and of subsequent coronary occlusion on this parameter are shown in figure 3 . While coronary sinus $\mathrm{TXB}_{2}$ levels did not change compared to baseline, there was a tendency in both groups for coronary sinus $\mathrm{TXB}_{2}$ to decrease in late occlusion and rebound during reperfusion (fig. 3). In the depleted group, $\mathrm{TXB}_{2}$ levels measured after 60 minutes of occlusion $(164 \pm 38)$ were significantly less than concentrations at 90 minutes after reperfusion $(370 \pm 112 \mathrm{pg} / \mathrm{ml})$. In the nonimmune serum group, $\mathrm{tXB}_{2}$ levels measured after 60 minutes of occlusion (148 \pm 14 ) were significantly less than levels at 60 minutes after reperfusion $(428 \pm 168 \mathrm{pg} / \mathrm{ml})$. However, the physiological significance of these differences is hard to evaluate in light of the variability in this parameter.

\section{Histopathologic examination}

Histopathologic examination of myocardium sampled at different sites within the midventricular tissue section showed no striking differences between the two 5 hour reperfused groups. Tissue samples from myocardium stained blue or brick red were confirmed as being viable. In contrast, nonstaining myocardium within the area-at-risk had undergone extensive necrosis characterized by hyalinization and loss of myofibrillar detail, patchy foci of contraction bands alternating with flocculent cytoplasm and nuclear changes. In both nonimmune serum and platelet-depleted animals, infarcted myocardium showed prominent leukocytic infiltration. A section from a thrombocytopenic animal demonstrating infarcted myocardium and leukocytic infiltration is shown in figure 4. 


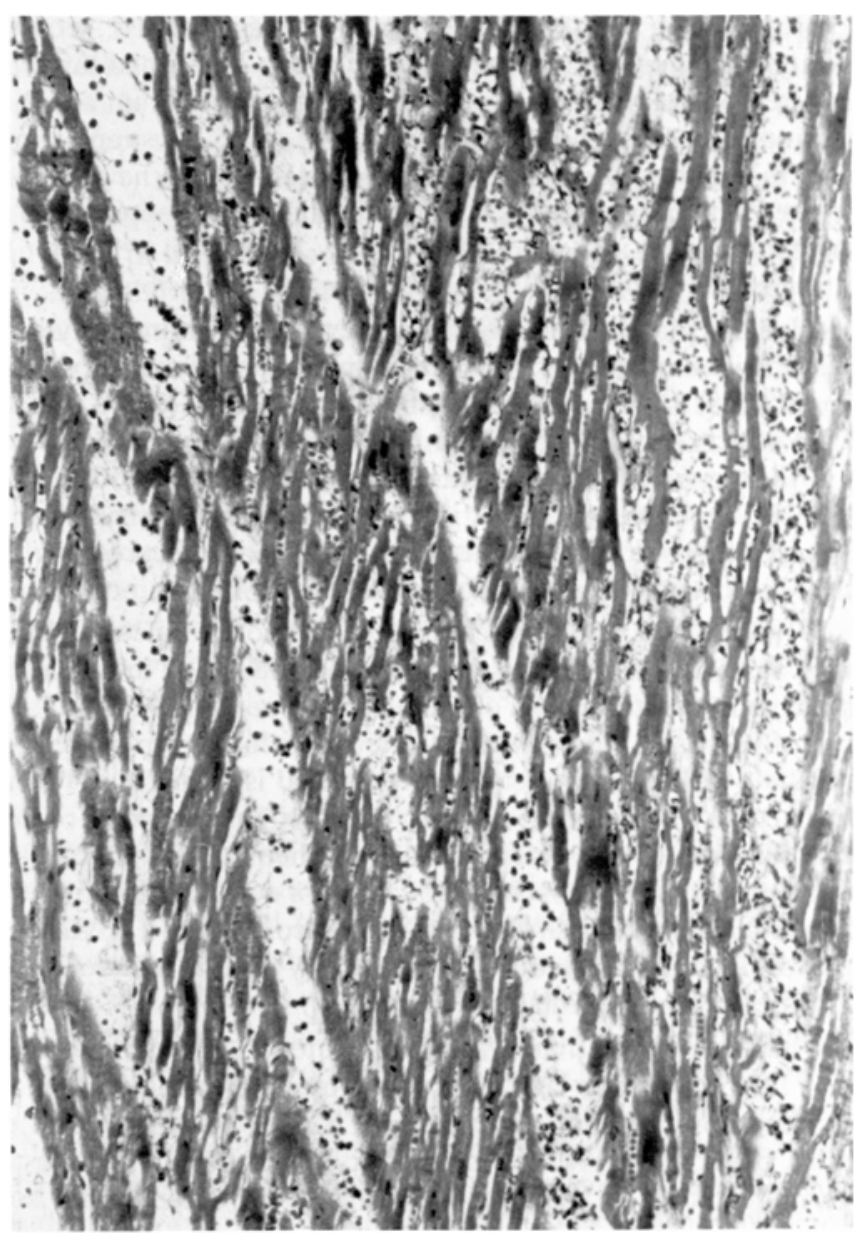

Fig. 4. A section of infarcted myocardium from a platelet depleted dog is shown. Structural disorganizaltion, cytoplasmic changes such as contraction bands, flocculent cytoplasm, and loss of nucki can be observed. A prominent leukocytic infiltrate is present.

\section{Discussion}

This study failed to demonstrate a protective effect of platclet depletion in myocardial ischemic injury due to occlusion/reperfusion of the LCCA. It is unlikely that a possible protective action of platelet depletion was obscured by other factors. Body weight and sex were controlled (22), and heart rate, mean arterial pressure and LCC.A coronary blood flow did not differ between groups. Due to control of the site of LCCA occlusion, the amount of left ventricle jeopardized is very consistant $(18,22,30)$, and did not differ between groups in this study. Regional myocardial blood flow was not studied, so variability between groups in this factor cannot be ruled out. Most of the previous investigations using this model of myocardial infarction utilized a 24-hour reperfusion period $(18,22,30)$. However, Romson et al. (29) and the present study have found that 6 - and 5-hour reperfusion periods in control 
animals produce infarcts of greater than $40 \%$ of the area-at-risk, equivalent to those observed at 24 hours. The nonimmune sheep serum group developed infarcts similar in size to those of saline treated animals (15) and nonimmune rabbit serum also had no effect on infarct size (29). Finally, agents other than the antisera, excepting supplemental pentobarbital, were not given to the dogs to avoid possible interference with the expression of ischemia as has been suggested with lidocaine (4). A lack of protection of jeopardized myocardium by severe thrombocytopenia has also been observed by Wilkerson et al. (36) in a coronary artery embolization model allowing 24 hours of complete occlusion.

In complete occlusion, platelet delivery to the developing infarct may be limited by low ischemic blood flow. Significant entry does occur, but it has been observed primarily on the borders of the infarct $(25,31)$. The relatively small [1- to 4-fold $(25,31)]$ platelet accumulation may minimize effects of thrombocytopenia. Since reperfusion allows exaggerated [10to 30 -fold $(21,30)]$ entry of platelets into the jeopardized region, the present occlusion/ reperfusion model of experimental infarction might be more likely to detect a plateletdependent component of tissue injury. Instead, no significant effect of platelet depletion was observed, which is consistent with results obtained with complete occlusion (36).

These results do not imply that stimulated platelets cannot produce ischemia. Injections of ADP into the coronary vasculature of pigs causes thrombosis in the microvasculature and ensuing myocardial infarction that is not observed in pigs rendered thrombocytopenic by $\mathrm{P}^{32}$ (19). In Langendorff-perfused rabbit hearts, addition of human platelets to the perfusate followed by activation with thrombin causes myocardial ischemia due to microthrombosis (1). Partial constriction of coronary arteries using circumferential occluders produces significant cyclical thrombosis with brief periods of ischemia (10). Electrical stimulation of the coronary intima produces thrombi characterized by a white tail composed predominantly of platelets entrapped in a fibrin meshwork and a head containing a mixture of platelets, red cells, and leukocytes (28). In this coronary artery injury model, platelet depletion prevents thrombosis and subsequent myocardial infarction (33).

Several reports have suggested that $\mathrm{TXA}_{2}$ contributes to myocardial ischemic injury and arrhythmias $(1,6,13,17,34)$. The lack of an effect of platelet depletion may be due to the inability of such depletion to depress circulating $\mathrm{TXB}_{2}$ levels. McDonald et al. (23) have reported a similar phenomenon where pulmonary hypertension, leukostasis and $\mathrm{TXB}_{2}$ production were not affected by platelet depletion (23). Perhaps other sources of $\mathrm{TXA}_{2}$ must be considered, such as circulating leukocytes (11). The perfused isolated heart has also been reported to produce thromboxane in a cardiac hypersensitivity model (2). Our "basal" canine coronary sinus $\mathrm{TXB}_{2}$ concentrations were close to those reported by others $(5,6)$ and changed only slightly upon LCCA occlusion and in the early phase of reperfusion. The lack of a significant elevation in coronary sinus $\mathrm{TXA}_{2}$ after 15 minutes of coronary occlusion is in agreement with Coker et al. (6). However, these investigators did detect a significant increase when $\mathrm{TXB}_{2}$ was measured in samples obtained from the coronary vein draining the ischemic region (6). Our studies may not reflect the actual course of events with respect to $\mathrm{TXB}_{2}$ contributed from the reperfused region, because the venous drainage from this area is diluted by venous blood from normally perfused myocardium. Furthermore, the increase in the $\mathbf{T X B}_{2}$ plasma concentrations in the late phase of reperfusion might have resulted in part from polymorphonuclear leukocytes that would accumulate in the injured reperfused myocardial region.

While ventricular arrhythmias were not quantitated in this study, significant ventricular ectopy was observed in both groups during early occlusion and upon reperfusion. Low $\mathrm{TXB}_{2}$ concentrations during late occlusion rising during reperfusion tend to support the hypothesis that $\mathrm{TXA}_{2}$ contributes to arrhythmogenesis $(6,17,24)$. An antiarrhythmic effect of aspirin 
has been reported $(6,24)$ and attributed to inhibition of $\mathrm{TXA}_{2}$ synthesis $(6)$. In addition, the thromboxane synthetase inhibitor, RO-22-4679, has been shown to reduce the incidence of ventricular fibrillation in conscious dogs (17). However, inhibition of $\mathrm{TXA}_{2}$ synthesis with imidazole did not affect the frequency of ectopic beats during reperfusion (5). In clinical studies, increased $\mathrm{TXA}_{2}$ has been reported during myocardial ischemia (14).

The present study was part of an investigation of inflammation in myocardial ischemia and reperfusion. The onset of irreversible tissue injury in regional ischemia is faster than that in global ischemia (32). This may be attributable to entry of blood components delivered by the residual blood flow via functional collateral vessels. Although both platelets and leukocytes enter the reperfused ischemic myocardium, platelet entry was not affected by ibuprofen treatment which reduced infarct size by $40 \%$ (30). Leukocyte entry, on the other hand, was reduced significantly by ibuprofen compared to controls (30). Anti-platelet serum (thrombocytopenia) did not reduce myocardial infarct size in either complete occlusion (36) or reperfusion models. Antisera to canine polymorphonuclear leukocytes significantly reduces the amount of irreversible tissue injury in this model $(15,29)$. In addition, a protective effect of neutrophil depletion has been reported recently in a complete coronary artery occlusion model (20). Entry of leukocytes into myocardial infarcts is an active chemotactic process stimulated by products of tissue injury such as complement fragments and products of arachidonic acid metabolism $(12,26)$. In the present study, prominent leukocytic infiltration was observed in infarcts from both thrombocytopenic dogs and controls. These studies would suggest that the leukocyte, rather than the platelet, is responsible for the inflammatory component of cell death in myocardial infarction.

Since the present studies were acute, wound healing was not examined. Platelets are among the first cells to adhere to injured surfaces in the microvasculature (35). The potential importance of collagen stimulated aggregation in thrombosis has been emphasized (12). However, recent studies suggest that antiplatelet drugs delay endothelial repair (3). A possible beneficial effect of platelets would not be detectable in the time frame of this study.

In conclusion, depletion of circulating platelets by $94 \%$ did not significantly affect the ultimate fate of myocardium jeopardized by LCCA occlusion plus reperfusion. Secondly, platelet depletion did not reduce coronary sinus $\mathrm{TXB}_{2}$ concentrations suggesting that $\mathrm{TXA}_{2}$ may be derived from sources other than the platelets. The importance of platelet-mediated thrombosis in the initiation of an ischemic event was not addressed in this study but is recognized as being of utmost importance in precipitating an acute myocardial infarction.

\section{Acknowledgcments}

This study was supported, in part, by a Grant-in-Aid from the American Heart Association of Michigan and by the National Institutes of Health, Heart, Lung, and Blood Institute, Grant \# HL27817, HL-19782.

S. R. Jolly was a Pharmacology-Morphology Fellow of the Pharmaceutical Manufacturers Association Foundation.

We gratefully acknowledge the expert assistance of Mr. W. J. Kane and Mr. E. M. Driscoll. We also thank Ms. Dixie Thomas for her aid in the preparation of this manuscript.

\section{References}

1. Addonizio VP, Wetstein L, Fisher CA, Feldman P, Strauss JF, Harken AH (1982) Mediation of cardiac ischemia by thromboxanes released from human platelets. Surgery 92:292-279

2. Allan G, Levy R (1981) Thromboxane and prostacyclin release during cardiac immediate hypersensitivity reactions in vitro. J Pharmacol Exp Ther 217:157-161 
3. Bomberger RA, DePalma RG, Ambrose TA, Manalo P (1982) Aspirin and dipyridamole inhibit endothelial healing. Arch Surg 117:1459-1464

4. Boudoulas H, Karayannacos PE, Lewis RP, Kakos GS, Kilman JW, Vasko JS (1978) Potential effect of lidocaine on ischemic myocardial injury: Experimental and clinical observations. J Surg Res 24:469-476

5. Burke SE, Antonaccio MJ, Lefer AM (1982) Lack of thromboxane $A_{2}$ involvement in the arrhythmias occurring during acute myocardial infarction in dogs. Basic Res Cardiol 77:411-422

6. Coker SJ, Ledingham IM, Parratt JR, Zeitlin IJ (1981) Aspirin inhibits the early myocardial release of thromboxane $B_{2}$ and ventricular ectopic activity following acute coronary artery occlusion in dogs. Br J Pharmacol 72:593-595

7. El-Maraghi N, Genton E (1980) The relevance of platelet and fibrin thromboembolism of the coronary microcirculation, with special reference to sudden cardiac death. Circulation 62:936-944

8. Factor SM, Cho S, Kirk ES (1982) Nonspecificity of triphenyltetrazolium chloride (TTC) for the gross diagnosis of acute myocardial infarction. Circulation 66:84A

9. Fitzpatrick FA, Gorman RR, McGuire SC, Kelly RC, Wynalda MA, Sun FF (1977) A radioimmunoassay for thromboxane $\mathrm{B}_{2}$. Analyt. Biochem 82:1-7

10. Folts JD, Crowell EB, Rowe GG (1976) Platelet aggregation partially obstructed vessels and its elimination with aspirin. Circulation 54:365-370

11. Goldstein IM, Malmsten CL, Samuelsson B, Weissman G (1977) Prostaglandins, thromboxanes and polymorphonuclear leukocytes. Mediation and modulation of inflammation. Inflammation 2:309-317

12. Hill JH, Ward PA (1971) The phlogestic role of C3 leukotactic fragments in myocardial infarcts of rats. J Exp Med 133:885-900

13. Hirsh PD, Campbell WB, Willerson JT, Hillis LD (1981) Prostaglandins and ischemic heart disease. Am J Med 71:1009-1026

14. Hirsh, PD, Hillis LD, Campbel! WB, Firth BG, Willerson JT (1980) Release of prostaglandins and thromboxane into the coronary circulation in patients with ischemic heart disease. N Engl J Med 302:6-10

15. Hook B, Kane W, Jolly S, Kunkel S, Abrams G, Lucchesi BR (1983) Effect of neutropenia on myocardial infarct size at 24 hours in the dog. Pharmacologist 25:217A

16. Hosko MJ, Gross GJ, Warltier DC (1977) Technique for precise graded arterial stenosis and occlusion. Basic Res Cardiol 72:651-659

17. Huddleston CB, Lupinetti FM, Laws KH, Collins JC, Clanton JA, Hawiger JJ, Oates JA (1983) The effects of RO-22-4679, a thromboxane synthetase inhibitor, on ventricular fibrillation induced by coronary artery occlusion in conscious dogs. Circ Res $52: 608-613$

18. Jolly SR, Abrams GD, Romson JL, Bailie MB, Lucchesi BR (1982) Effects of lodoxamide on ischemic reperfused myocardium. J Cardiovase Pharmacol 4:441-448

19. Jorgensen L, Rowsell HC, Hovig T, Glynn MF, Mustard JF (1967) Adenosine diphosphate-induced platelet aggregation and myocardial infarction in swine. Lab Invest 17:616-644

20. Ksiezycka E, Maroko PR (1983) Reduction by antineutrophil serum of experimental infarct size. Clin Res 31:666A

21. Laws KH, Clanton JA, Starnes VA, Lupinetti FM, Collins JC, Oates JA, Hammon Jr JW (1983) Kinetics and imaging of Indium-111-labeled autologous platelets in experimental myocardial infarction. Circulation 67:110-116

22. Lucchesi BR, Burmeister W, Lomas T, Abrams GD (1976) Ischemic changes in the canine heart as affected by the dimethyl quaternary analog of propranolol, UM-272 (SC27761). J Pharmacol Exp Ther 199:310-328

23. McDonald JWD, Ali M, Townsend ER, Cooper JP (1983) Thromboxane synthesis by sources other than platelets in association with complement-induced pulmonary leukostasis and pulmonary hypertension in sheep. Circ Res 52:1-6

24. Moschos CB, Haider B, DeLaCruz C, Lyons MM, Regan TJ (1978) Antiarrhythmic effects of aspirin during nonthrombotic coronary occlusion. Circulation 57:681-684

25. Moschos CB, Lahir K, Lyons M, Weisse AB, Oldewurtel HA, Regan TJ (1973) Relation of microcirculatory thrombosis to thrombus in the proximal coronary artery: Effect of aspirin, dipyridamole and thrombolysis. Am Heart J 86:61-68 
26. Pinckard RN, O'Rourke RA, Crawford MH, Grover FS, McManus LM, Ghidoni JJ, Storrs SB, Olson MS (1980) Complement localization and mediation of ischemic injury in baboon myocardium. J Clin Invest 66:1050-1056

27. Rittenhouse-Simmons S, Deykin D (1976) Isolation of membranes from normal and thrombintreated gel-filtered platelets using a lectin marker. Biochem Biophys Res Comm 426:688-696

28. Romson JL, Bush LR, Haack D, Lucchesi BR (1980) The beneficial effects of oral ibuprofen on coronary artery thrombosis and myocardial ischemia in the conscious dog. J Pharmacol Exp Ther 215:271-278

29. Romson JL, Hook BG, Kunkel SL, Abrams GD, Schork MA, Lucchesi BR (1983) Reduction of the extent of ischemic myocardial injury by neutrophil depletion in the dog. Circulation 67:1016-1023

30. Romson JL, Hook BG, Rigot VH, Schork MA, Swanson DP, Lucchesi BR (1982) The effect of ibuprofen on accumulation of Indium-111-labeled platelets and leukocytes in experimental myocardial infarction. Circulation 66:1002-1011

31. Ruf W, McNamara JJ, Suehiro A, Suehiro G, Wickline SA (1980) Platelet trapping in myocardial infarct in baboons: therapeutic effect of aspirin. Am J Cardiol 46:405-412

32. Schaper J (1979) Ultrastructure of the myocardium in acute ischemia. In: Schaper W (ed) The pathophysiology of Myocardial Perfusion, p 581, Elsevier-North Holland, New York

33. Schumacher WA, Buda AJ, Lucchesi BR (1984) Streptokinase thrombolysis in experimental coronary artery thrombosis: Pattern of reflow and effect of a stenosis. Intl J Cardiol, 6:615-627

34. Smith EF, Lefer AM, Aharony D, Smith JB, Magolda RL, Claremon D, Nicolaou KC (1981) Carbocyclic thromboxane $A_{2}$ : aggrevation of myocardial ischemia by a new synthetic thromboxane $A_{2}$ analog. Prostaglandins 21:443-456

35. Walker LN, Ramsay MM, Bowyer DE (1983) Endothelial healing following defined injury to rabbit aorta, depth of injury and mode of repair. Atherosclerosis 47: 123-130

36. Wilkerson RD, Couran PB, Shaikli BS (1983) Severe thrombocytopenia does not limit myocardial infarct size or ventricular arrhythmias after coronary artery occlusion. Fed Proc 42:1360A

Received June 14, 1984

Authors' address:

Benedict R. Lucchesi, Ph.D., M.D. Department of Pharmacology, M6322 Medical Science Building I, The University of Michigan Medical School, Ann Arbor, Michigan 48109 (U.S.A.) 